\title{
Design and construction of a prototype for the analysis of vibrations in an induction motor for the detection of faults
}

\section{Diseño y construcción de un prototipo para el análisis de vibraciones en un motor de inducción para la detección de fallas}

GARRIDO, Javier†*, ESCOBEDO-TRUJILLO, Beatris, MARTÍNEZ-RODRÍGUEZ, Guillermo Miguel and SILVA-AGUILAR, Oscar Fernando

Universidad Veracruzana, Mexico.

ID $1^{\text {st }}$ Author: Javier, Garrido / ORC ID: 0000-0002-3134-6405, Researcher ID Thomson: T-2722-2018, CVU CONACYT ID: 599539.

ID $1^{\text {st }}$ Co-author: Beatris, Escobedo-Trujillo / ORC ID: 0000-0002-8937-3019, Scopus ID: 54417142300, CVU CONACYT ID: 173174.

ID $2^{\text {nd }}$ Co-author: Guillermo Miguel, Martínez-Rodríguez / ORC ID: 0000-0003-2186-2323, Researcher ID Thomson: O7148-2018, Scopus ID: 57203338661

ID $3^{\text {rd }}$ Co-author: Oscar Fernando, Silva-Aguilar / ORC ID: 0000-0002-5109-3193, CVU CONACYT ID: 338659

DOI: $10.35429 /$ JTD.2020.13.4.27.33

Received: January 25, 2020; Accepted June 30, 2020

\begin{abstract}
The contribution of this work is to present the design of a prototype integrated by an induction motor, a data acquisition system, accelerometers and control devices for stop and start, to generate and identify different types of faults by means of vibration analysis. in the domain: time, frequency or frequency-time, through the use of the Fourier Transform, Fast Fourier Transform or Wavelet Transforms (wavelet transform). In this prototype, failures can be generated in the induction motor such as: unbalance, different types of misalignment, mechanical looseness, and electrical failures such as broken bars or short-circuited rings, an example of a misalignment failure is presented to show the process of analysis and detection.
\end{abstract}

\begin{abstract}
Resumen
La contribución de este trabajo es presentar el diseño de un prototipo integrado por un motor de inducción, un sistema de adquisición de datos, acelerómetros y dispositivos de control para el paro y arranque, para generar e identificar diferentes tipos de fallas mediante el análisis de vibraciones en el dominio: del tiempo, de la frecuencia o frecuencia-tiempo, mediante el uso de la transformada de Fourier, Transformada rápida de Fourier o la transformadas de onduletas (transformada wavelet). En este prototipo se pueden generar fallas en el motor de inducción como: desbalance, diferentes tipos de desalineamiento, soltura mecánica, y fallas eléctricas como barras rotas o anillos en corto circuito, se presenta un ejemplo de una falla de desalineamiento para mostrar el proceso de análisis y detección.
\end{abstract}

\footnotetext{
$\dagger$ Researcher contributing as first author.
} 


\section{Introduction}

Electric motors demand $45 \%$ of electricity consumption worldwide, activating pumps, fans, compressors and mechanical traction in industrial facilities, infrastructure plants and large buildings (Motor Summit, 2014). Motors that work under normal operating conditions suffer wear and tear and over time they come to present failures that can lead to: unscheduled stoppages in production, environmental problems or safety problems that could cause deaths. To prevent these problems, solutions such as corrective, preventive and predictive maintenance arise.

Motors generally do not fail instantaneously, the failure occurs gradually, that is, different characteristics of a healthy engine begin to be noticed.These characteristics are: vibrations, heat and noise, if after a while the failure is not attended to, it can cause that the computer stops. One of the strategies to detect when a failure is initiating is preventive maintenance.

Predictive maintenance offers the advantage of detecting a failure, there are different types of analysis that can be carried out in predictive maintenance such as: Vibration analysis, oil analysis, temperature monitoring, etc., the most used in industries are monitoring from vibrations to rotating equipment. Mechanical vibration is the harmonic movement of a machine, or element of it, in any direction of space from its position of equilibrium. (MorenoGarcía, Becerra-Vargas, \& Rendón-Echeverri, 2015). In motor, vibration can be generated by:

Degradation due to exceeding the useful life of the motor.

Failures in the mechanical part: failure in the bearings, misalignment of the rotor shaft.

Worn or damaged gears.

Stator Failures: Open circuits or short circuits in the stator windings.

Human errors when performing poor engine maintenance.

Severe work environments (dust, humidity, water).
Prototypes for vibration analysis have been developed by Zhaoxia et al. (2009) where applying an analysis with the Wavelet Transform, synchronously comparing signals in the time and frequency domain. The work presented by (Hua. 2011), performs a design for the acquisition of data and processing of mechanical vibration signals using LabVIEW software. The presented prototype has the advantage of being able to do different tests at different load values, and apart from being able to do a vibration analysis, an analysis of current signatures can be done.

The main objective of this work is to present the design of a prototype for the analysis of vibrations in induction motors where different types of failures can be detected using techniques in the time domain, frequency or frequency-time and the severity of this This prototype was developed in the laboratory of the Faculty of Engineering of the Universidad Veracruzana, Coatzacoalcos campus.

This work is organized as described below. In section 2 motor failures are presented and because they can be detected using vibration analysis, in section 3 the programming of the data acquisition system is explained, in section 4 the prototype for vibration analysis and the results when simulating a misalignment fault in a motor, the last section contains the conclusions.

\section{Induction motor failures}

The question Why do engines fail? To answer the previous question, the main causes can be listed:

- Components in engines degrade over time and stress from the length of time they are in operation.

- Electrical insulators degrade over time due to imbalances in voltage, humidity, and temperature within the motor.

Contact between moving surfaces causes wear, wear is affected by dirt, moisture, corrosive vapors, and wear is accelerated by lack of lubrication.

- $\quad$ Apply a mechanical overload to the motor. 
The types of failures in a motor are classified as: Mechanical and Electrical, to detect this type of failure it is necessary to know that by design and construction the motors have an electrical and mechanical symmetry for the coupling of the stator and the rotor. Vibration monitoring is based on detecting faults in this symmetry which produces changes in normal engine operations such as:

- Vibrations.

- $\quad$ Increase in temperature.

- $\quad$ Variations in torque.

- $\quad$ Acoustic noise.

- $\quad$ Speed variations.

These changes have to be identified by a pattern in order to detect the type of failure and the severity of the failure. These patterns can be in frequency, duration, amplitude and phase shift. The most common engine failures in the industry are:

- Degradation due to exceeding the useful life of the motor.

- $\quad$ Failures in the mechanical part.

Failures are usually related to the environment or work cycle and occur during some transitory process, which is when the mechanical and electrical stresses to which it is subjected are greater (Cabanas, 1998).

Failures can be measured based on the factors that cause them: bearing failures account for $40 \%$, related stator failures equal $38 \%$, rotor related failures $10 \%$, and other failures are within than $12 \%$ of engine failures (Toliyat, Nandi, Choi, \& Meshgin-Kelk)

\section{Cryo programming}

The data acquisition system consists of a Compact Rio (CRio) system, which is programmed through LabVIEW software, the CRio controller is programmed in the Real time and FPGA interface, depending on the sampling frequency is the mode of programming, if the sampling frequency is greater than $1 \mathrm{kHz}$, it is programmed in FPGA mode, Before programming the CRio, the first step is to create a project within which the cards installed in the controller are organized as shown in Figure 1.

\section{FPGA Interface Programming}

In Figure 2, the FPGA interface programming is shown, this program stores the measurements of three sensors which were mounted on the motor to measure mechanical vibrations, the program creates a vector of $n$ readings and stores the data in a memory FIFO, the memory size depends on the sample time and sample rate, the stored data is sent to the Host interface.

\section{Host interface programming.}

The Host interface program is shown in Fig. 3, this program receives the data from the FIFO memory of the FPGA program, which is plotted in the time domain, for the vibration analysis the Transform tool is used. Fourier (TF), which graphs the aromonics of the vibration signal, finally the data is stored in TDMS format, to be able to analyze it in Excel or Matlab.

The stored data can be analyzed using the Fast Fourier Transform or the Waveform Transform, using Matlab software to analyze other types of faults. 


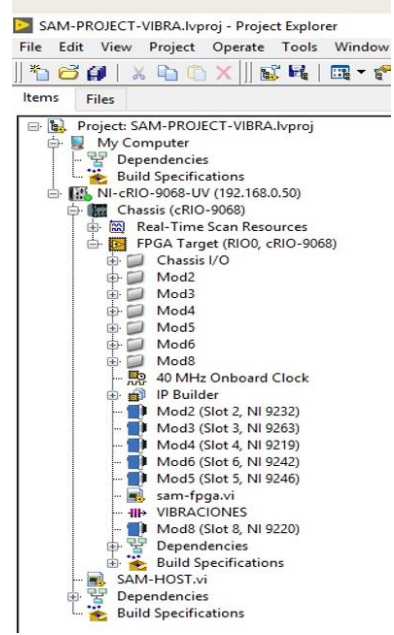

Figure 1 Compac Rio Project

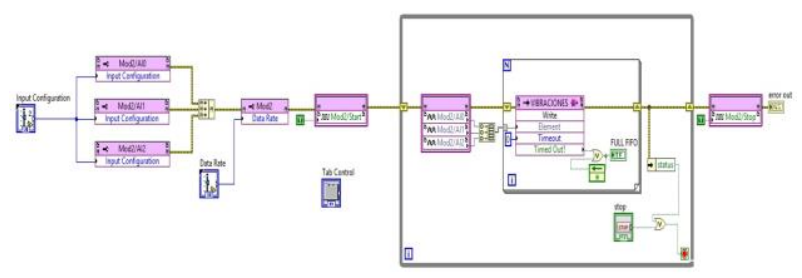

Figure 1 FPGA programming

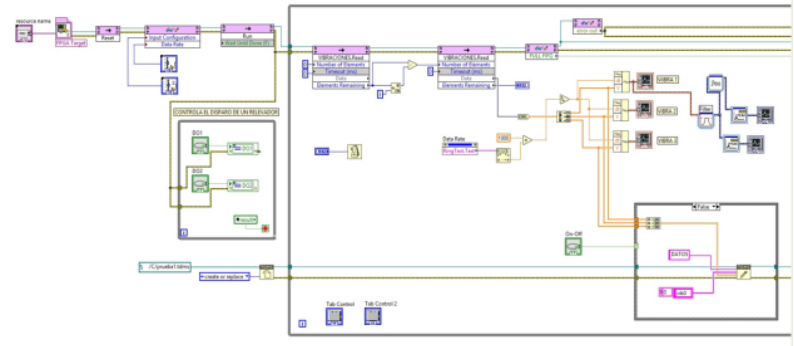

Figure 2 Host programming

In Fig. 4, the Human-Machine Interface (HMI) of the vibration monitoring system is shown.

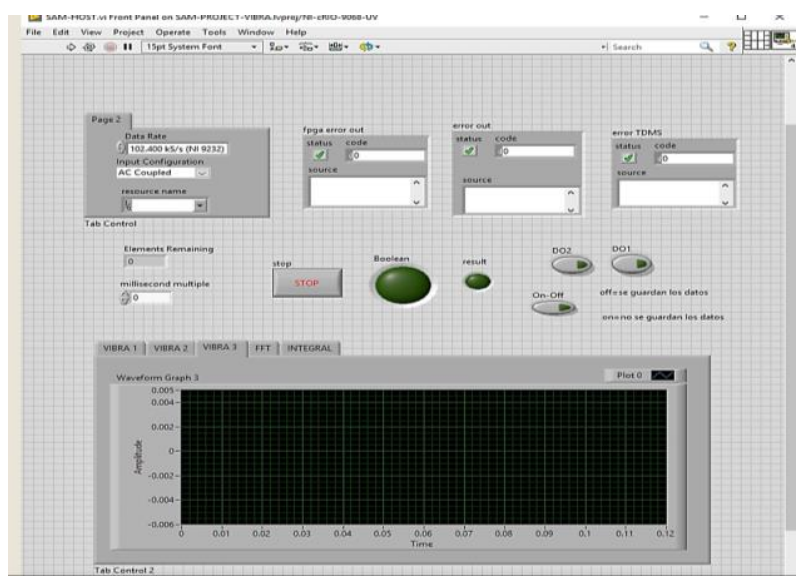

Figure 4 HMI for vibration analysis

\section{Platform for vibration analysis}

The prototype architecture is shown in Figure 5, where you can see the CRio data acquisition system, the accelerometer type sensors, the control module for turning the engine on or off and the HMI to monitor vibrations. The data of the equipment to be used is shown in Table 1 .

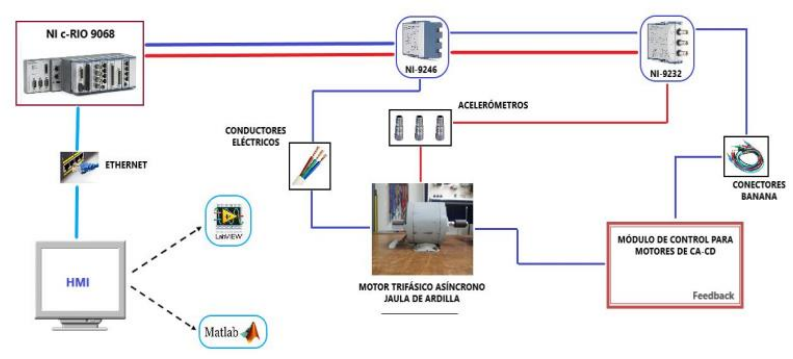

Figure 5 Prototype architecture to measure vibrations

In Fig. 6 the induction motor coupled to a prony brake is shown, with which different load levels can be generated and the changes in the amplitude of mechanical vibrations can be analyzed.

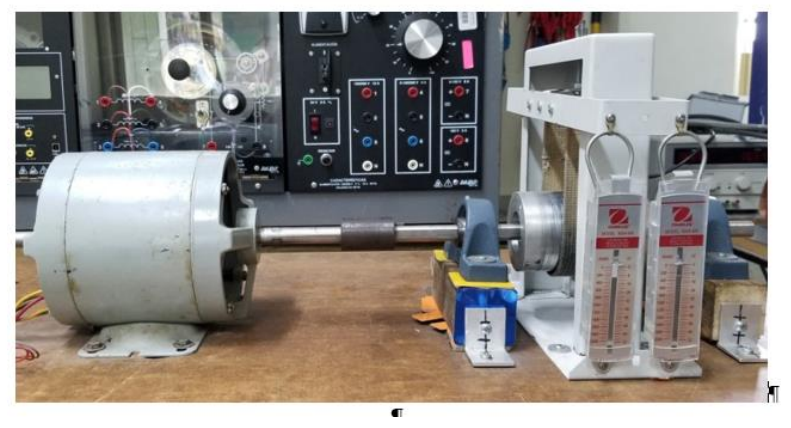

Figure 6 Induction motor and prony brake

To perform the vibration analysis, the sensors were installed in three positions: Axial, Radial, Tangential and Axial, Axial is the direction that is parallel to the arrow, Radial is the direction that goes from the sensor to the center of the arrow and Tangential is 90 degrees from the radial and tangent to the arrow as shown in Fig 8

In Fig. 7, the module of the feedbak brand Contactor Panel 65-123 is shown, which is used to control the stop and start manually or remotely through the HMI. 

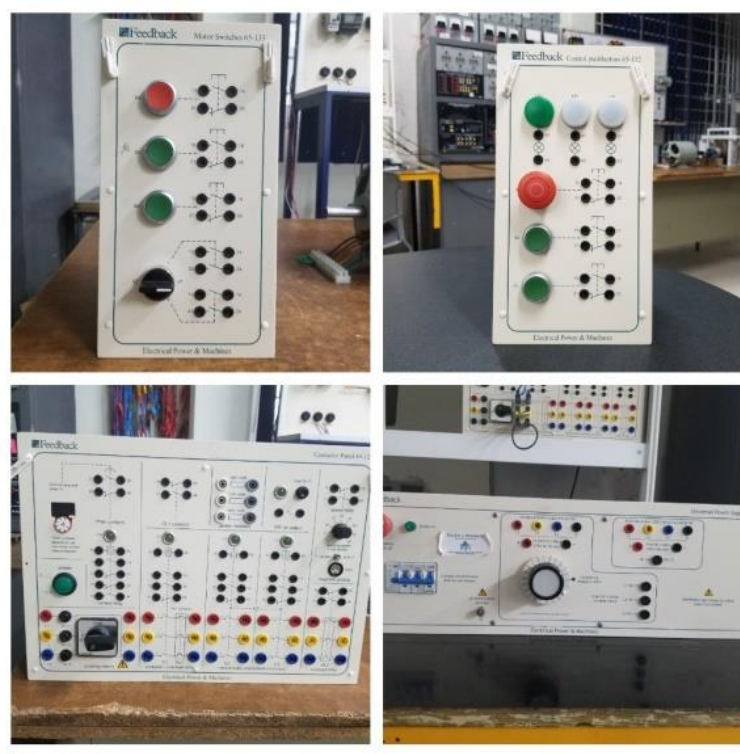

Figure 7 Feedback control modules

\section{Results}

Different types of failures can be generated in the prototype, for this work only an angular misalignment failure of the shaft is presented as an example, which generates vibrations, noise, temperature increase and premature damage to the bearings, depending on the severity of the failure is the magnitude of the previous variables.

\begin{tabular}{|c|c|}
\hline Equipment & Description \\
\hline Induction motor & $\begin{array}{l}\text { Brand: Labvolt, } 4 \text { Poles, } 60 \mathrm{~Hz}, 1 / 4 \\
\text { hp, } 1670 \mathrm{rpm}, 208 \mathrm{~V}, 1.2 \mathrm{~A}, 3 \\
\text { phases. }\end{array}$ \\
\hline CRIO-9068 & $\begin{array}{l}\text { Brand: National Instrument, } 667 \\
\text { MHz Dual-Core CPU, 512 MB } \\
\text { DRAM, } 1 \text { GB, Zynq-7020. }\end{array}$ \\
\hline NI-9232 & $\begin{array}{l}\text { Brand: National Instrument, } 3 \mathrm{AI}, \pm \\
30 \mathrm{~V}, 24 \text { Bit, } 102.4 \mathrm{kS} / \mathrm{s} / \mathrm{ch} \\
\text { Simultaneous. }\end{array}$ \\
\hline NI-9375 & $\begin{array}{l}\text { Brand: National Instrument, } 16 \text { DI } \\
\text { / } 16 \text { DO, } 30 \text { VDC, } 7 \mu \mathrm{s} \text { DI sink, } 500 \\
\mu \text { s, DO Source. }\end{array}$ \\
\hline $\begin{array}{l}\text { Power supply 60- } \\
105\end{array}$ & $\begin{array}{l}\text { Brand: Feedback, Power Source, 0- } \\
220 \text { Vac. }\end{array}$ \\
\hline $\begin{array}{l}\text { Panel Contactor } \\
65-123\end{array}$ & $\begin{array}{l}\text { Brand: Feedback, } 324 \text { Vac power } \\
\text { control for contacts }\end{array}$ \\
\hline Accelerometers & $\begin{array}{l}\text { Brand: IMI, 2-Pin Accelerometers, } \\
\text { 100mV / g, ICP® (IEPE), 15kHz. }\end{array}$ \\
\hline
\end{tabular}

Table 1 Equipment characteristics

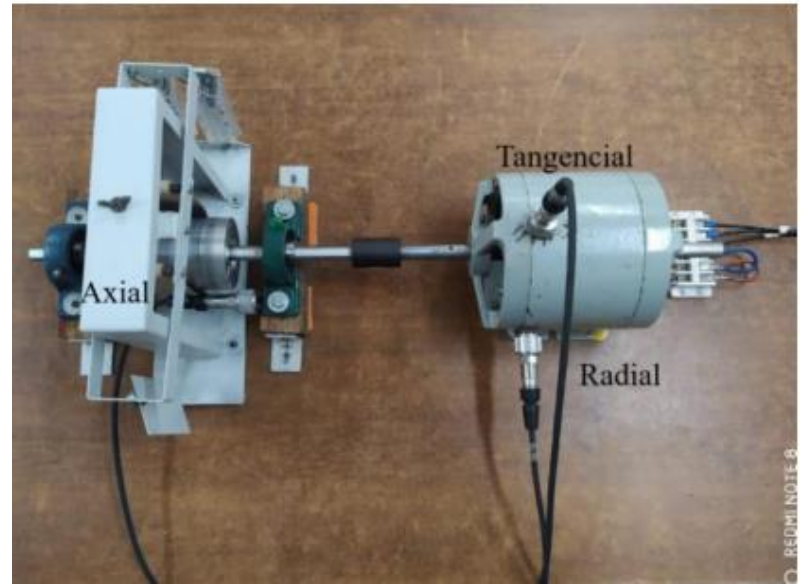

Figure 8 Vibration sensors

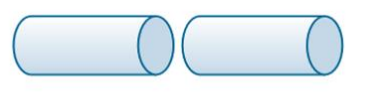

a)

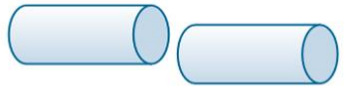

b)

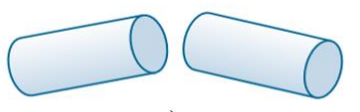

c)

Figure 9 Types of misalignment A) ideal, b) parallel c) angular (Luedeking)

Shaft misalignment failure (angular), characterized by high axial vibration $180^{\circ}$ out of phase through the coupling will typically have an axial vibration of 1xRPM (abbreviated as $1 \mathrm{x}$ ) where RPM is the revolutions per minute and $2 \mathrm{x}$. However, it is not unusual for both $1 \mathrm{x}, 2 \mathrm{x}$, or $3 \mathrm{x}$ to dominate in frequency domain analysis. Different types of motor shaft misalignment are shown in Fig. 9

The first step to perform the vibration analysis is to observe the signal in the time domain and in the frequency domain, but the conditions of the place must be taken into account, such as the base where the equipment is mounted and the force with the screws are tight, because these conditions cause abnormal vibration conditions.

To check the misalignment, the healthy motor is compared against the faulty motor, so the vibrations of the healthy motor are measured as shown in Fig. 11, to determine the frequency of the harmonics the nominal motor speed is used (1800 RPM) and are converted to cycles per second (cps) so that $1 \mathrm{x}=30 \mathrm{cps}, 2 \mathrm{x}=60 \mathrm{cps}$ and $3 x=90$. In Fig. 12 the motor with misalignment is shown in which it can be observed that the $1 \mathrm{x}$ harmonics and $2 \mathrm{x}$, and $3 \mathrm{x}$ are those that dominate the spectrum so it can be verified that there is a misalignment problem. 


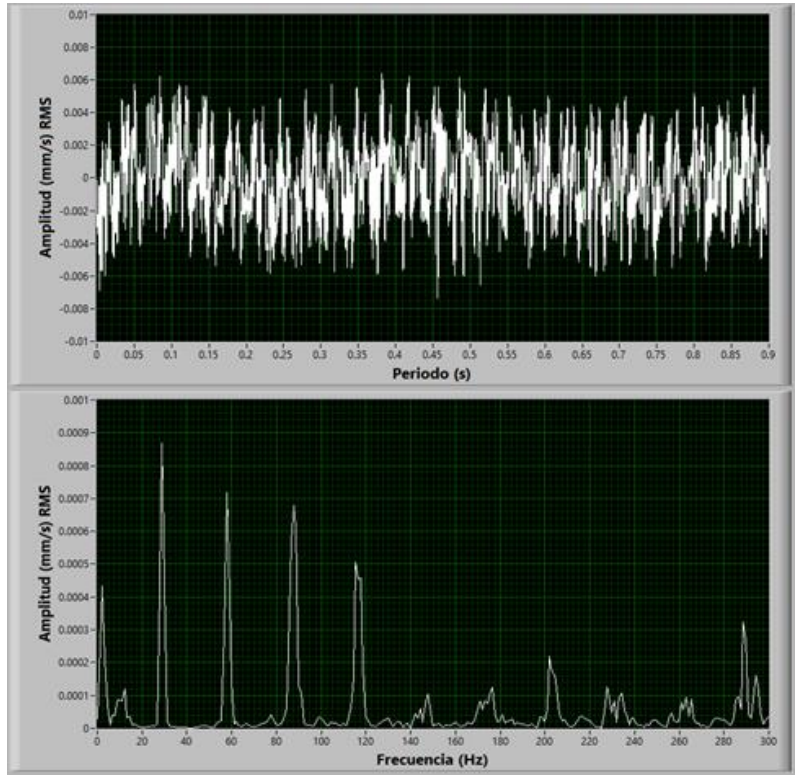

Figure 11 Frequency and time domain speed spectrum of radial accelerometer (healthy motor)

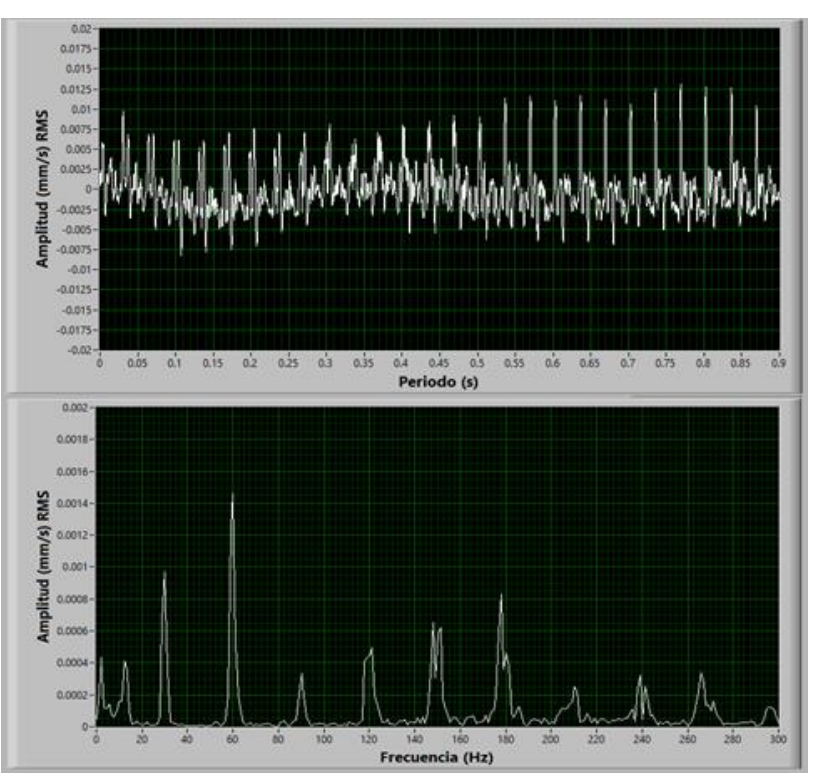

Figure 12 Axial accelerometer frequency and time domain velocity spectrum (misaligned motor)

Table 2 compares the peaks of the $1 \mathrm{x}, 2 \mathrm{x}$ and $3 x$ harmonics of the healthy motor and the motor with misalignment.

\begin{tabular}{|c|c|c|c|}
\hline \multicolumn{4}{|c|}{ Motor without fault } \\
\hline $\begin{array}{l}\text { Sensor } \\
\text { position }\end{array}$ & $\begin{array}{l}\text { Rotor } \\
(\mathrm{Hz})\end{array}$ & frequency & $\begin{array}{l}\text { Amplitude } \\
(\mathrm{mm} / \mathrm{s}) \mathrm{RMS}\end{array}$ \\
\hline \multirow[t]{3}{*}{ Axial } & & 28.18 & $0.975 \times 10^{-3}$ \\
\hline & & 56.36 & $1.45 \times 10^{-3}$ \\
\hline & & 84.54 & $0.35 \times 10^{-3}$ \\
\hline \multicolumn{4}{|c|}{ Misaligned motor } \\
\hline $\begin{array}{l}\text { Sensor } \\
\text { position }\end{array}$ & $\begin{array}{l}\text { Rotor } \\
(\mathrm{Hz})\end{array}$ & frequency & $\begin{array}{l}\text { Amplitude } \\
(\mathrm{mm} / \mathrm{s}) \mathrm{RMS}\end{array}$ \\
\hline \multirow[t]{3}{*}{ Axial } & & 28.18 & $0.88 \times 10^{-3}$ \\
\hline & & 56.36 & $0.72 \times 10^{-3}$ \\
\hline & & 84.54 & $0.68 \times 10^{-3}$ \\
\hline
\end{tabular}

Table 2 Comparative table of motor harmonics
From Table 2, the absolute difference in percentage of the $1 \mathrm{x}, 2 \mathrm{x}$ and $3 \mathrm{x}$ harmonics of the healthy motor and the faulty motor is calculated, remaining as:

- The 1X axial harmonic $(28.18 \mathrm{~Hz})$ presents a difference of $9.74 \%$.

- The 2X axial harmonic $(56.36 \mathrm{~Hz})$ presents a difference of $50.34 \%$.

- The axial harmonic 3X $(84.54 \mathrm{~Hz})$ presents a difference of $94.28 \%$.

\section{Conclusions}

The monitoring of rotating equipment is of utmost importance within industries and mechanical vibration analysis is one of the most important techniques used.

In this work, a prototype was designed and built to perform vibration analysis tests in which the Fourier transform was used to detect different types of faults, in this work only this technique is shown but the prototype is open to use other tools of analysis as current signatures.

In this work, an angular unbalance fault was generated in the motor, which could be detected using the LabVIEW software in real time.

\section{Acknowledgments}

To the Electrical Engineer Samuel Cabrera Fuentes for his support in the preparation of this work.

This work is a collaboration between the academic bodies UV-CA466-MechanicalElectrical and UV-CA-412-Engineering and Modeling of Energy Processes.

\section{References}

Cabanas, M. F. (1998). Técnicas para el mantenimiento y diagnóstico de máquinas eléctricas rotativas, España: Marcombo.

Hua, Z. (2011, August). Application of LabVIEW in the design of data acquisition and signal processing system of mechanical vibration. In 2011 International Conference on Mechatronic Science, Electric Engineering and Computer (MEC) (pp. 2551-2554). IEEE.

GARRIDO, Javier, ESCOBEDO-TRUJILLO, Beatris, MARTÍNEZRODRÍGUEZ, Guillermo Miguel and SILVA-AGUILAR, Oscar Fernando. Design and construction of a prototype for the analysis of vibrations in an induction motor for the detection of faults. Journal of Technological Development. 2020 
Moreno-García, F. E., Becerra-Vargas, J. A., \& Rendón-Echeverri, C. A. (2015). Diseño de un sistema de análisis temporal y espectral para detectar fallas por vibración en motores eléctricos. Revista Facultad de Ingeniería, 24, 41-51.

Motor Summit (2014). 5th International Motor Summit for Energy Efficiency powered by S.A.F.E. Recuperado de: http://www.motorsummit.ch/sites/default/files/2 $017-$

06/ms14_tagungsband_komplett_web.pdf

Zhaoxia, W., Fen, L., Shujuan, Y., \& Bin, W. (2009, November). Motor fault diagnosis based on the vibration signal testing and analysis. In 2009 Third International Symposium on Intelligent Information Technology Application (Vol. 2, pp. 433-436). IEEE.

Toliyat, H. A., Nandi, S., Choi, S., \& MeshginKelk, H. (2012). Electric machines: modeling, condition monitoring, and fault diagnosis: CRC press. 